\title{
PROJETO PARCEIROS DA CRIANÇA: A EXPERIÊNCIA DA FORMAÇÃO DE EDUCADORES NA COMUNIDADE DE HELIÓPOLIS, SÃO PAULO
}

\author{
*Marisa Irene Siqueira Castanho, **Takako Tachibana Arima
}

\section{RESUMO}

Este artigo apresenta o processo de formação de educadores locais de um projeto de educação não formal da comunidade do Heliópolis, São Paulo, no período de 2002 a 2005. O projeto estruturado como um espaço de educação complementar à escola para o atendimento de 260 crianças e jovens de 7 a I 4 anos tinha como objetivo estimular e fortalecer o acesso à cultura e à educação como um bem cultural. As atividades desenvolvidas por meio de oficinas temáticas, de esportes, de atividades culturais e de orientação de estudos eram criadas a partir de momentos de planejamento, que envolviam, de um lado, educadores e dirigentes locais, e de outro, professores e alunos da Universidade São Marcos, com apoio do Instituto GM. Orientadas pelas diretrizes do trabalho coletivo e interdisciplinar, as ações se voltaram ao desenvolvimento de atitudes, de competências e de habilidades para o planejamento educacional com foco na reflexão sobre problemas do cotidiano, fortalecendo as relações e propiciando o ganho de autonomia, a valorização do conhecimento e o empoderamento local.

Palavras-chave: Educação não formal. Formação de educadores. Projeto social.

\section{ABSTRACT}

This article presents the process of formation of local educators for a non-formal educational project at the community of Heliópolis, São Paulo, from 2002 to 2005 . Structured as a place for education complementary to the regular school, aimed at 260 children and adolescents (age range from 7 to I4 years-old), the project's main goal was to stimulate and strengthen the access to culture and education as a cultural good. The activities developed through thematic workshops, sports and leisure, cultural and recreational excursions, and study guidance were created based on planning involving educators and local leaderships, as well as professors and students of the São Marcos University, all of them with the support of the Instituto GM. Oriented by the parameters of collective and interdisciplinary work, the actions were focused on the development of attitude, competences and abilities for the educational planning, centered on autonomy and on the reflection about every day problems, causing relationships to strengthen and allowing the valorization of knowledge and local empowerment.

Key words: Non formal education. Educator formation. Social project.

\footnotetext{
* Doutora em Psicologia Escolar e do Desenvolvimento Humano pelo Instituto de Psicologia da USP. Coautora da proposta político-pedagógica implantada no Projeto Parceiros da Criança, em Heliópolis, São Paulo, no período de 2002-2005. Atualmente docente e pesquisadora do Programa de pós-graduação stricto sensu em Psicologia Educacional do Centro Universitário FIEO Osasco, Av. Franz Voegeli, 300, Vila Yara, bloco Prata, Io subsolo - Osasco-SP - 060020-I9o - tel.: (II) 365I-99I4-e-mail: marisa.irene@unifieo.br. ** Pedagoga. Técnica do Núcleo de Programas e Projetos Sociais da Diretoria de Extensão da Universidade São Marcos e coautora da proposta político-pedagógica implantada no Projeto Parceiros da Criança, em Heliópolis, São Paulo, no período de 2002-2005-e-mail: tatarima@yahoo.com.br.
} 


\section{INTRODUÇÃO}

A partir dos anos 1990 novas alternativas de ações em espaços de educação não formal surgem como decorrência da iniciativa particular de grupos, empreendimentos e organizações não governamentais, com o objetivo de apoiar e implementar programas de desenvolvimento e processos de aprendizagem em grupos, em direção à valorização das culturas em uma sociedade regida pelas mudanças econômicas e no mundo do trabalho (GOHN, 200I).

Em janeiro de 2002, por meio de uma parceria com a União dos Núcleos, Associações e Sociedade de Moradores de Heliópolis e São João Glímaco (UNAS) e o Instituto General Motors do Brasil (IGM), a Universidade São Marcos (USM) assumiu o acompanhamento da implantação de uma proposta sócio-educacional no Projeto Parceiros da Criança, na comunidade de $\mathrm{He}-$ liópolis, São Paulo. O Projeto atendia cerca de 260 crianças e adolescentes de 7 a I4 anos com o objetivo de desenvolver habilidades, competências e atitudes pessoais, de participação democrática e de socialização em um contexto social marcado por expressivos índices de pobreza, desemprego e subemprego.

Após os primeiros contatos com os dirigentes e educadores locais, bem como com a instituição financiadora, desenvolveu-se uma proposta sócio-educacional denominada Re-Griar (CENTRO DE EDUCAÇÃO E GULTURA, 2002), visando contemplar as expectativas gerais: aprendizagem dos conteúdos da escolarização formal e acompanhamento dos estudos; proteção contra a marginalidade e violência; acesso ao conhecimento e à cultura; espaço de lazer e conhecimento, entre outros. Se, de um lado, o projeto se justificava pela qualidade no atendimento das crianças e jovens, por outro, entendeu-se que o foco deveria ser a formação e o acompanhamento dos educadores locais para garantir essa qualidade.

Assim, a proposta incluiu, desde o início, um programa de capacitação continuada dos educadores por meio da participação de docentes de diferentes cursos de graduação da universidade e dos alunos desses cursos em atividade de estágio: Psicologia, Pedagogia, Letras, Informática, Arquitetura, Engenharia Ambiental, Fisioterapia. O termo "capacitação" foi uma denominação geral para os encontros promovidos com o intuito de realizar o planejamento das atividades a serem desenvolvidas, tendo em vista a finalidade do Projeto.
Neste artigo, apresenta-se a implantação e desdobramentos dessa proposta, com ênfase nos momentos de capacitação, que acabou por se constituir como um contínuo processo de formação dos educadores locais ao longo de quatro anos.

\section{PROBLEMATIZAÇÃO}

A UNAS organizou-se a partir da década de 1980 com foco na luta dos moradores pelo direito à moradia. Ampliou sua atuação em meados dos anos 1990 para questões relacionadas ao combate à pobreza, à urbanização da favela e, em especial, a programas educacionais dirigidos à criança e ao adolescente. O Projeto Parceiros da Criança foi resultado dessa iniciativa local.

A parceria com a universidade foi considerada pelos dirigentes locais como esforço legítimo de luta em direção ao "empoderamento" da comunidade, o que vinha explícito em suas falas: "a presença da Universidade no espaço da comunidade legitima a busca pelo conhecimento".

Nesse sentido, o educador foi considerado figura central nesse processo visto como elemento potencialmente capaz de desenvolver uma proposta de educação em sintonia com a realidade local. Se, de um lado, isto o tornava mais apto a desenvolver um trabalho pedagogicamente diferenciado por não se pautar nos currículos formais da escola, por outro, ao fazer parte do contexto, o educador estava submetido às mesmas condições culturais, sociais, políticas e econômicas.

O primeiro desafio implicou em capacitar o educador local para uma atividade semelhante à do professor, habilitando-o às prerrogativas do trabalho pedagógico, como o planejamento de ações intencionais, conscientes, dirigidas para um fim específico. Ao mesmo tempo, era necessário marcar a diferença, uma vez que ele seria um mediador entre os acontecimentos da vida cotidiana na comunidade e o conhecimento não formalizado pelos planos escolares. Com isso, cabia-lhe identificar os conhecimentos relevantes para a finalidade das aprendizagens que se propunham.

A objetivação do trabalho pressupunha uma margem de autonomia, uma vez que o mesmo se concretizaria pelo conhecimento da realidade das crianças e adolescentes como base de um planejamento contínuo do trabalho. Tal autonomia se colocava em contraposição com a necessidade de se submeter a processos de 
formação em capacitação. Este se constituiu no segundo desafio: os pressupostos de ganho de autonomia do educador local deveriam compor com os diferentes níveis de domínio em áreas específicas do conhecimento por parte dos professores da universidade. Era necessário que ambas as partes caminhassem na construção de um outro saber, que englobasse as várias formas de conhecimento. Além disso, era necessário considerar o que seria específico da educação não formal e em que direção (objetivos e metas) as ações deveriam ser conduzidas.

O terceiro desafio dizia respeito à desconstrução dos níveis hierárquicos já estabelecidos e que implicava no risco de uma relação de "cima para baixo", em que o conhecimento vindo da universidade criava um contraponto com as carências da comunidade. Era preciso considerar que os professores e a equipe da universidade eram pouco habituados a uma produção coletiva de conhecimento, com dificuldades de traduzi-lo para a linguagem e realidade locais.

Como promover, então, o trabalho de formação do educador? Nos quatro anos de parceria, várias mudanças ocorreram ao longo do percurso, na maneira de conduzir as capacitações em busca de possibilidades de criação de novas relações entre a teoria e a prática, de valorização da experiência do educador, na tentativa de construir e ampliar a participação coletiva dos envolvidos.

\section{AÇÕES DESENVOLVIDAS}

Os momentos de capacitação congregaram os profissionais, os estagiários e os educadores locais e constituíram o foco do trabalho de parceria. O princípio dialético da articulação entre ação-reflexão-ação foi possibilitando que os resultados fossem tomados como base para promover as mudanças necessárias nas ações com o intuito de refletir a realidade e a pertinência das ações.

Um primeiro momento era o das capacitações propriamente ditas, realizadas no início, ao longo e ao final de cada ano. Tais capacitações eram realizadas no espaço da universidade e consistiam em encontros necessários para o cultivo do trabalho coletivo voltado ao planejamento das atividades, de forma a garantir a visão interdisciplinar do projeto, tendo como convergência eixos temáticos e a aproximação dos conteúdos à realidade.
O segundo, de execução e acompanhamento das atividades, consistia no trabalho integrado de equipe para garantir a operacionalização do planejamento no próprio Projeto. Tal trabalho requeria vários níveis de interlocução, que envolviam também a clientela, os dirigentes locais e os funcionários para os ajustes necessários à implementação, de forma a se tornarem condizentes com as possibilidades.

Por último, o momento de avaliação, que consistia na sistematização de dados, observações e registros acumulados nos vários momentos de implantação e acompanhamento das atividades com a finalidade de manter e ou implementar as mudanças necessárias no planejamento, no final de cada período.

\section{O ANO DE 2002: IMPLANTAÇÃO DA PROPOSTA}

A proposta socioeducacional Re-Criar orientou-se pelos seguintes princípios: vida em sociedade, atividade produtiva e experiência subjetiva. Tais princípios emanavam dos eixos da educação na sociedade contemporânea sugeridos pela UNESCO (DELORS, I996): o aprender a conhecer, a fazer, a viver e a ser; e dos Parâmetros Curriculares $\mathrm{Na-}$ cionais (MEC, 2000), com ênfase na saúde, ética e cidadania. O objetivo principal era promover ações voltadas para o autoconhecimento nos níveis individuais e coletivos: quem sou eu; o que é o Projeto Parceiros da Criança; eu e a comunidade; o Projeto e a comunidade.

Partiu-se de um levantamento de dados para a caracterização da clientela e diagnóstico da realidade, por meio da elaboração e aplicação de questionários semiestruturados aos educadores, crianças e adolescentes, pais e egressos para levantamento de dados sobre a concepção do projeto e as expectativas de resultados.

Ao longo de todo o processo, eram elaborados relatórios; registros e anotações (diário de bordo) dos dados de acompanhamento das ações no projeto; registros fotográficos; atas de reuniões.

Em relação à avaliação, realizaram-se dois momentos com os educadores, em junho e em dezembro, buscando apreender a qualidade do planejamento e do trabalho, visando afirmar metas, objetivos e ações.

Dentre os principais resultados dessas avaliações, tem-se a destacar: não convergência do conceito 
de educação não formal; distância entre o planejamento e a ação pedagógica; problemas de comunicação; presença de dois projetos paralelos, manhã e tarde; realização de ações pedagógicas como mera execução de tarefas, recortadas, tratadas superficialmente ou por falta de domínio, ou de preparo ou de envolvimento do educador; reações negativas dos educadores e de disputa na atenção das crianças desencadeadas pela presença do estagiário; esvaziamento e falta de sentido na realização de algumas propostas e atividades quando não adequadamente compreendidas e ou mediadas pelos educadores locais.

Alguns aspectos positivos evidenciavam que houvera crescimento coletivo no desenvolvimento da proposta e, a despeito das dificuldades, o grupo reconhecia a importância das parcerias, manifestando o interesse na continuidade e no aprimoramento do trabalho.

\section{O ANO DE 2003}

A ênfase foi a redefinição de metas e objetivos, acrescentando-se aos princípios emanados dos quatro pilares da UNESGO e dos PGNs, os direcionamentos presentes no Estatuto da Criança e do Adolescente (ECA) (BRASIL, I990); o conceito de educação não formal como instrumentação para a inserção na sociedade, no mundo do conhecimento e do trabalho em atitude de composição com a escola; e a proposição de uma ecologia do desenvolvimento humano entendida como dinâmica que demarca os valores e pauta as modalidades de ação dos sujeitos em interação nos espaços sociais, culturais e políticos (BROFFEN-BRENNER, I996).

Dentre as metas privilegiaram-se: o desenvolvimento de um conhecimento compartilhado a respeito da finalidade do Projeto; a criação de mecanismos de avaliação do impacto das ações no desenvolvimento de conteúdos, habilidades, competências e atitudes não só nas crianças e adolescentes, mas as ocorridas nos próprios educadores e pais em relação a seus papéis e responsabilidades. O objetivo central foi o acompanhamento dos educadores e o estímulo no ganho de autonomia no desenvolvimento das ações pedagógicas e maior afinação com as propostas e necessidades da comunidade.

Para a operacionalização das ações, a equipe organizou os trabalhos de capacitação em torno da temática "O homem, seus sonhos, sua história, em busca de sua constru- ção", cujo eixo da evolução do homem em seu processo civilizatório implicava em conhecimentos nas áreas da História, Ciências, História da Arte, Geografia, Religião, Literatura, entre outras. A seleção de conteúdos e de atividades buscava apoio nessas áreas como forma de ampliar o próprio conhecimento sobre a comunidade e sua história.

A sistemática de avaliação contínua regida pelo princípio da associação entre ação-reflexão-ação permaneceu ao longo de todo o ano, tendo por instrumentos: roteiros e questionários semiestruturados aplicados em vários momentos de capacitação e encontros com os educadores, as crianças e os adolescentes. Foram incluídos os egressos e os representantes do Conselho de Pais. As escolas foram contatadas de maneira mais sistemática. Os principais itens versavam sobre: a dimensão do projeto, a abrangência da atuação e das intervenções; a visão dos consultados a respeito das instituições parceiras; a visão sobre as crianças e adolescentes, sobre as famílias e sobre os educadores e funcionários.

Os resultados apontaram diferentes expectativas e concepções do Projeto: para os pais, abrigo, alimentação, segurança, acompanhamento escolar, proteção para os filhos; para as crianças, espaço de brincadeiras; para os educadores, possibilidade de dar uma vida melhor para as crianças e desenvolver a cidadania; para os líderes comunitários, espaço de empoderamento e acesso a uma educação de qualidade; para os professores da universidade, acesso ao conhecimento como emancipação; para o IGM, visão empresarial e de gerenciamento voltada para o resgate da cidadania, complementação escolar e alimentação do maior número de crianças e de adolescentes em um programa de responsabilidade social.

Como consequência das diferentes expectativas, ocorriam divergências no planejamento e nas ações; dificuldades de comunicação em diferentes níveis; dificuldades na circulação de informações e orientações emanadas da universidade.

Em relação à visão sobre cada uma das instituições parceiras: coexistência de duas visões a respeito da UNAS, um como espaço de mobilização política das pessoas e dos grupos voltada para o empoderamento da comunidade; outra como entidade assistencialista voltada ao bem estar da população; em relação a universidade, coexistência de duas visões: a orientação teórica e prática que dela emanava vista como 
inovação e promoção de crescimento e desenvolvimento para os envolvidos e a da falta de maior aproximação com a realidade local e maior consolidação da parceria; o IGM visto como parceria de grande força, financiador do Projeto e idealizador na educação de jovens carentes, mas também como entidade distante na comunicação e no acompanhamento das ações.

Alguns resultados apontavam um impacto positivo no desenvolvimento e aprendizagem das crianças e adolescentes, por meio dos seguintes aspectos: o Projeto educa para a vida, ensina a ver o mundo com outros olhos, amplia a consciência para as drogas e a violência, amplia a responsabilidade e o respeito ao outro e ao ambiente; provoca mudanças no comportamento e atitudes da criança para melhor; desenvolve habilidades para os estudos.

Esse conjunto de dados foi sistematizado em um primeiro relatório, que respondeu à necessidade de organização de dados até então dispersos a respeito da presença do Projeto e de seu impacto na comunidade de Heliópolis (GENTRO DE EDUGAÇÃO E CULTURA, 2003).

\section{O ANO DE 2004}

O foco principal foi a composição de uma nova equipe de educadores pelos seguintes critérios: disponibilidade de tempo integral, formação no Magistério e/ou Pedagogia; envolvimento com a comunidade. Tais critérios visavam formar uma equipe com condições de assumir o trabalho com maior preparo e autonomia em relação à universidade. Os princípios norteadores foram os da concepção de trabalho por projetos (FONSEGA, 200I; HERNÁNDEZ et al., 200I; ZEN, 200I).

As capacitações passaram a contar com a participação de representantes das crianças e adolescentes, bem como dos pais. A contribuição da universidade passou a ter uma característica de orientação técnica para a elaboração de cada projeto individual e da organização de todos em torno de um tema aglutinador: "Migração social, diversidade cultural, cidadania e identidade no processo de construção do conhecimento".

De todo esse trabalho nasce a reelaboração coletiva da proposta original, que passou a se denominar: Proposta político-pedagógica "Re-Criar" (PROJETO PARCEIROS DA GRIANÇA, 2004) com revisão da mis- são, metas e objetivos; discussão do regimento interno; reorganização das crianças por faixas etárias mais próximas, visando facilitar a identificação dos interesses comuns; reorganização de grade horária; implementação da figura de oficineiros para garantir a qualidade técnica das atividades e de um coordenador pedagógico local para garantir a qualidade da comunicação.

Outras ações implementadas foram: reuniões com pais e Conselho de Pais; visitas domiciliares; participação em eventos culturais e políticos da comunidade; reuniões entre os parceiros; ações e visibilidade do Projeto; integração com outros projetos de educação não formal e com as escolas.

As avaliações ao final do primeiro e do segundo semestres se deram em vários níveis: com os educadores, avaliação dos projetos individuais e sua pertinência em relação ao tema aglutinador; com as crianças e adolescentes, avaliação das expectativas e realizações no Projeto, a opinião dos pais e a própria opinião sobre a importância do Projeto em suas vidas; com os pais o regimento interno, o andamento dos trabalhos e o estabelecimento de contrato verbal de co-responsabilidade na educação dos filhos; com a equipe da universidade, análise de relatórios de acompanhamento dos educadores.

Os resultados mostraram que o planejamento ocorreu de forma mais participativa; as atividades nas oficinas foram enriquecidas de conteúdos e estratégias mais adequadas, levando a uma melhor motivação das crianças; os educadores mostraram-se mais conscientes e atentos ao desenvolver ações pedagógicas, focando olhar e escuta nas crianças; houve melhor resposta às capacitações semanais e à presença dos professores e dos estagiários da universidade; a presença do Conselho de Pais e das crianças contribuiu para afirmar a direção e a proposta do Projeto; houve repercussão local, com convites para as crianças e adolescentes se apresentarem em espaços da comunidade.

Algumas dificuldades permaneceram e novas apareceram: a dificuldade de integrar os vários assuntos em torno de um projeto coletivo; a diversidade de temas resultando na busca de muitas alternativas para saídas culturais, sem o cuidado e aprofundamento necessários para garantir uma integração dos conhecimentos.

Ao término de 2004, o cenário estava configurado. Os educadores mostravam-se participativos, com maior liberdade e responsabilidade para um trabalho mais flexível e autônomo. Pela primei- 
ra vez, participaram de um evento científico, o Fórum Mundial de Educação, apresentando suas experiências (CASTANHO et al., 2004).

\section{ANO DE 2005}

O início do ano foi marcado pelo movimento rumo à eleição de um eixo temático, o da "Cultura Brasileira", eleito por unanimidade como propício para a solidificação do conhecimento em espaço de educação não formal. $O$ foco na multiculturalidade favorecia a identificação e aceitação das diferentes culturas (indígena, afro-brasileira e do branco) presentes na realidade da comunidade. Os princípios emanavam da educação reflexiva e problematizadora de Paulo Freire (FREIRE, I996) atualizados pela noção de "comunidade de aprendizagem como esforço endógeno, cooperativo e solidário" na identificação de problemas e busca de soluções (GENPEG, 2003).

Desde o início e ao longo do ano, os objetivos focalizaram a ampliação das ações promotoras da integração do Projeto com a comunidade e da aproximação entre as áreas educacional, administrativa, da cozinha e de manutenção, de maneira a incentivar a comunicação, o entendimento e a participação. Outro objetivo forte foi o de incentivar o fazer como meio para o aprendizado. Fazer entendido como aprimoramento técnico, criativo e lúdico.

Foram mantidas as capacitações mensais com a participação de crianças, do Conselho de Pais, da equipe de educadores locais e da equipe da universidade, bem como as capacitações continuadas semanais, por oficinas; foram acrescentadas capacitações específicas para funcionários da cozinha e da manutenção; foram introduzidas reuniões quinzenais específicas para discussão de questões internas como papel do educador, do estagiário, dificuldades enfrentadas pelo grupo; foram incorporados à equipe, educadores com experiências em projetos comunitários/sociais; foi ampliada a capacitação digital de educadores e funcionários em geral para a utilização de aplicativos (Paintbrush, Internet, PowerPoint), criação e utilização de e-mails, acesso a sites educativos para pesquisa.

O estudo e a vivência de vários aspectos das culturas indígena, afro-brasileira e europeia foi feito por meio da arte, artesanato, teatro, danças, músicas, ritos religiosos, literatura, lendas, contos, cordéis, culinária, favorecendo a expressão estética e a postura ética de todos os envolvidos, com repercussões favoráveis na divulgação do trabalho na comunidade (Festival da Paz no CEU Meninos; Caminhada pela Paz; Festa Julina na Rua; II Mostra Cultural da Semana da Criança; Bienal de Arquitetura; Mostra Cultural da UNAS; I Micareta). Pela primeira vez, o Projeto abriu-se para a inclusão, recebendo crianças com necessidades especiais.

Nas atitudes do cotidiano o grupo se mostrava mais receptivo aos assuntos ligados à diversidade de manifestações religiosas, culturais e preparado para enfrentar dificuldades por parte das crianças de lidar com elementos de rejeição, abandono e desqualificação social: ser índio, ser negro, ser branco; ter pouco valor, pertencer a "famílias desestruturadas".

Os resultados em todos os níveis e momentos de avaliação iam indicando uma maior clareza do valor do trabalho coletivo, da atribuição de sentido e renovação de valor simbólico dos conteúdos selecionados pelos próprios educadores, de maior domínio e realce das relações entre as estratégias e as posições dos indivíduos no campo das interações.

O grupo fechou o ano considerando que o caminho estava traçado e que a escolha por um trabalho articulado e de característica interdisciplinar resultava da persistência das ações coletivas, das reflexões, da coragem de mudar e/ ou de persistir.

\section{DISCUSSÕES E FINALIZAÇÃO}

Partilhamos da ideia de que o espaço social é um espaço de resistência e lutas, de contradição e movimento. De que o acesso ao conhecimento em um mundo globalizado não se dá de maneira verticalizada pela imposição de um grupo cultural a outro.

Entendemos que o educador afinado com a ideia de movimento distancia-se de soluções pragmáticas e utilitaristas e investe no enfrentamento da realidade complexa não se furtando a enxergar a multiplicidade de manifestações no campo cultural e social, identificando caminhos de construção de sentido para si e para o outro.

O desafio da formação do educador na experiencia relatada implicou, antes de tudo, na superação de preconceitos: a ideia de domínio de conhecimento por parte da universidade; de ausência de conhecimento no espaço comunitário; de que somente esse conhecimento poderia elevar o nível de inserção social das crianças e adolescentes. 
A forma como o processo foi sendo conduzido desde o início era regida pela visão dialética da práxis do educador e a sintonia fina que o programa de capacitação deveria ter no acompanhamento desse educador, com uma visão de educação como processo e não apenas como produto.

A premência, desde o início, para uma avaliação de resultados e para bons resultados na avaliação, colocava em risco o processo e seduzia para que se chegasse a respostas imediatas por meio de ações reprodutivistas, com ênfase no fazer pragmático e sem criticidade.

Entender que o acesso ao conhecimento é a porta de abertura para o mundo não significa que basta se submeter àquele para romper com os obstáculos que impedem o desenvolvimento e a humanização do homem.

No caso do Projeto Parceiros da Criança, optou-se por colocar em xeque o conhecimento e só "sucumbir" a ele mediante efetivos efeitos nas respostas de todos os envolvidos. Foi preciso desconstruir hierarquias e ir construindo em seu lugar uma base de confiança coletiva.

\section{AGRADECIMENTOS}

À comunidade Parceiros da Criança, pela convivência e construção do possível. Em especial, a Antonia Cleide Alves, atual presidente da UNAS, fundamental liderança na busca pelo desejo feito realidade.

\section{REFERÊNCIAS BIBLIOGRÁFICAS}

BRASIL. Estatuto da Criança e do Adolescente. Lei n. 8.069 de I3 de julho de I990. Brasília: Congresso Nacional.

BRASIL. MEC (Secretaria da Educação Fundamental). Parâmetros Curriculares Nacionais. $2^{\mathrm{a}}$ ed., Rio de Janeiro: DP\&A, 2000.

BROFFENBRENNER, U. A ecologia do desenvolvimento humano. Porto Alegre: Artes Médicas, I996.

CASTANHO, M. I. S.; ARIMA, T. et al. Proposta político-pedagógica Re-Criar e seus efeitos na formação dos educadores locais: transformando atores em autores. Fórum Mundial de Educação São Paulo - Educação Cidadã para uma Gidade Educadora. São Paulo, abr. 2004.

CENPEC. Muitos lugares para aprender. Centro de Estudos e Pesquisas em Educação, Cultura e Ação Comunitária - GENPEG - São Paulo: GENPEG/Fundação Itaú Social/Unicef. 2003.
GENTRO DE EDUCAÇÃO E GULTURA (USM). Proposta socioeducacional “Re-criar". Pró-Reitoria de Assuntos Comunitários/Programa de Responsabilidade Social Centro de Educação e Cultura - Universidade São Marcos. São Paulo, fev. 2002. (apostilado).

GENTRO DE EDUGAÇÃO E GULTURA (USM). Relatório de Acompanhamento e Avaliação (2002-2003). São Paulo: Universidade São Marcos/CEG, abr. 2003.

DELORS, J. Educação: um tesouro a descobrir (relatório à UNESCO da Comissão Internacional sobre a Educação para o Século XXI), Lisboa: Asa, I996.

FREIRE, P. Pedagogia da Autonomia: saberes necessários à prática educativa. Rio de Janeiros: Paz e Terra, I996.

FONSECA, L. L. O universo na sala de aula: uma experiência em pedagogia de projetos. Porto Alegre: Ed. Meditação, 200I.

GOHN, M. G. Educação Não-Formal e Cultura Política. 2 ed., São Paulo: Cortez, 200 I.

HERNÁNDEZ, F.; VENTURA, M. A organização do currículo por projetos de trabalho: o conhecimento é um caleidoscópio. Porto Alegre: Artmed, $200 \mathrm{I}$.

PROJETO PARGEIROS DA GRIANÇA. Proposta Político-Pedagógica Re-Criar. São Paulo: USM - Núcleo de Programas e Projetos Sociais/UNAS, 2004.

ZEN, M. I. D., org. Projetos pedagógicos: cenas da sala de aula. Porto Alegre: Ed. Meditação, 2001. 